\title{
Organizações multilaterais, redes de governança e políticas educacionais
}

\author{
Olinda Euangelista' \\ Programa de Pós-graduação em Educação da Universidade do Oeste Catarinense, \\ Professora Senior. Universidade Federal de Santa Catarina, Professora Uoluntária. \\ https://orcid.org/0000-0001-5360-2521 \\ Eneida Shiroma ${ }^{2}$ \\ Universidade Federal de Santa Catarina, Professora Titular \\ https://orcid.org/0000-0002-0506-7058
}

Recebido em 30 de outubro de 2019 Aceito em 30 de outubro de 2019 Publicado em 12 de dezembro de 2019

0 Dossiê em suas mãos reúne um conjunto de textos que tematizam as relações entre a produção de políticas educacionais em diferentes países e o modo pelo qual diretivas emanadas de organizações multilaterais são apropriadas por seus governos. Deriva de investigações desenvolvidas por pesquisadores brasileiros, portugueses e britânicos, relativas a três importantes organizações - Banco Interamericano de Desenvolvimento (BID), Organização para Cooperação e Desenvolvimento Econômico (OCDE), Banco Mundial (BM) - e suas formas de atuação na América Latina, particularmente no Brasil, e na União Europeia.

Os dois primeiros artigos referem-se à política do BID para a educação pública. Em Avaliação externa na Rede Municipal de Florianópolis: uma tentativa de amestramento do trabalho docente pelo capital, Thiago Salgado Vaz de Lima e Adriana D'Agostini analisam as implicações para o trabalho docente decorrentes da política de avaliação externa na Rede de Ensino de Florianópolis, financiada pelo BID desde 2012. Nessa parceria, a Secretaria de Educação contratou o Centro de Políticas Públicas e Avaliação da Educação (CAEd) da Universidade Federal de Juiz de Fora para formular e analisar os resultados da avaliação. A lógica presente na avaliação sugerida e a atuação do CAEd em organizações privadas evidenciam vínculos estreitos com frações do capital e seu caráter de classe burguês. 0 desdobramento de tal lógica repercute sobre o trabalho dos professores municipais,

Pós-doutora em Educação na Universidade do Minho, Portugal; Doutora em Educação pela Pontificia Universidade Católica de São Paulo (PUC-SP); Mestra em Educação pela Pontifícia Universidade Católica de São Paulo (PUC-SP).

2 Pós-doutora em Ciências Humanas pela Universidade de Oxford; Doutora em Educação pela Universidade Estadual de Campinas. 
responsabilizando-os pelos escores alcançados nos exames e intensificando as formas de controle de sua atividade pedagógica. 0 segundo texto, 0 projeto de educação do Banco Interamericano de Desenvolvimento, de Mariano Moura Melgarejo e Eneida Oto Shiroma, complementa o artigo anterior, pois discute o projeto de Educação do BID, recuperando elementos de sua história, forma organizativa e contratos contraídos no Brasil. Após a análise de diretrizes gerais, marcos setoriais e projetos para o setor, os autores constataram que sua política tem em vista prover aos alunos as habilidades requeridas pelo mercado, o que implica estreitar a formação docente. Esse processo se esconde sob o pretexto do combate à pobreza. Contudo, de fato, dissemina a necessidade de controlar o trabalho docente, para o que sugere reformas curriculares, avaliações em larga escala e coaching. Acompanha essa diretriz a flexibilização da gestão, a destruição da carreira do magistério dado que vem sendo substituída por políticas meritocráticas -, e a implementação de políticas de accountability e vouchers. Inúmeras são as formas de privatização que atingem a Rede Municipal de Ensino de Florianópolis, da escolha dos materiais didáticos à terceirização da gestão de algumas de suas escolas. Em conjunto, os dois artigos demonstram a ingerência, cada vez maior, das agências financeiras nos rumos da educação pública, cuja intenção é a de reconverter a formação e balizar o trabalho docente por meio da produção de resultados (SHIROMA; EVANGELISTA, 2014; 2015).

No trabalho $A$ educação na lógica do Banco Mundial e a formação para a sociabilidade capitalista, Aline Inácio Decker e Olinda Evangelista põem em relevo o projeto de formação humana elaborado pelo Banco Mundial, entre 2000 e 2014, para o Brasil. As publicações dessa agência têm em vista construir consenso em torno de suas propostas emaranhadas à desqualificação profunda do professor e da escola pública. Dessa desqualificação decorrem recomendações para a Educação que - pela via do professor alinham a formação da classe trabalhadora aos moldes flexíveis da sociabilidade capitalista. Segundo a lógica bancomundialista, a Educação deve assumir a tarefa de combater a pobreza simultaneamente à promoção do desenvolvimento econômico. Recuperando a Teoria do Capital Humano, o BM propõe uma educação de "classe mundial" subordinando-a às demandas do capital no século XXI. 0 movimento operado pelo Banco elide as razões de sua proposta, pois incidem diretamente na relação capital-trabalho e na produção da barbárie por meio da educação, forjando a sociabilidade necessária ao seu projeto.

Os cinco artigos a seguir examinam as diretrizes da OCDE e sua apropriação tanto no Brasil quanto na União Europeia. Rodrigo da Silva Pereira, em Proposições da OCDE e sua materialização na política educacional brasileira, toma as proposições da agência, em especial no que diz respeito ao Programa Internacional de Avaliação de Estudantes (PISA), e sua materialização na política educacional brasileira. Tematiza a gestão e a avaliação do sistema educacional e as recomendações traçadas para a Educação Básica pública. Após submeter a escrutínio documentos do governo federal, evidenciou as articulações entre o 
Estado e a OCDE, assinalando o aprofundamento das relações políticas e educacionais entre ambos e a incorporação pelo Brasil das proposições da Organização na gestão educacional e nas avaliações externas. Mecanismos de controle aparecem como incentivo à qualidade de ensino, obscurecendo os interesses do capital que a eles subjazem. Higson Rodrigues Coelho e Rogério Gonçalves de Freitas, no artigo Futuro antecipado na educação: OCDE e controle do conhecimento global, focam um outro aspecto da atuação da OCDE. Seu recente projeto de controle do conhecimento no campo educativo vem sendo difundido por meio de um discurso que pretende antecipar o futuro. A agência tem se destacado pelos poderosos instrumentos de avaliação educacional que elabora, a exemplo do PISA, que é mais que um programa de avaliação em larga escala. Do ponto de vista dos autores, ele funciona como vitrine da OCDE e expressa seu controle político e econômico do conhecimento global. 0 jargão "futuro antecipado" se constitui como um movimento para criação de novas cadeias de produção de valor, "vaticínio" dos novos "profetas" da educação neoliberal.

Os artigos que se sucedem abordam as políticas da OCDE para a União Europeia. Jenny Ozga e Margaret A. Arnott, no texto Governando além do PISA: conhecimento, redes e narrativas, analisam a atuação da OCDE na Escócia, evidenciando que novas prescrições para a gestão da educação compõem seu projeto de Governança de Sistemas Educacionais Complexos (GSEC). Com ele, a agência procura combinar as melhores práticas de organização de sistemas, mesclando-as com narrativas de equidade e qualidade baseadas em mensurações que criam uma "robusta base de evidências" para política educacional. 0 artigo discute o conteúdo e a direção do GSEC considerando sua adoção na política educacional na Escócia, com base no relatório da OCDE 2015, sobre a melhoria da educação, e dos resultados do PISA 2016. As autoras debatem o conteúdo das recomendações, especialmente no que tange aos conceitos de conhecimento, redes e narrativas, e como são traduzidos na política, ademais de identificarem algumas das tensões no âmbito do próprio projeto de governança da OCDE. Martin Lawn, em Governança da educação na União Europeia: redes, dados e standards, produz uma reflexão acerca do modo pelo qual, na União Europeia (UE), ao longo do tempo, ocorreram convergências políticas entre as nações. Conquanto ela não comande tal convergência, tampouco seja capaz de fazê-lo, o fato é que vem governando a área. As tecnologias governamentais conduzem, sem desconsiderar as ambiguidades da UE, a uma governança eficaz e silenciosa. Que políticas e que atores participam desse processo de construção e regulação da educação Europeia? Para o autor, redes complexas de experts públicos e privados, com apoio das novas tecnologias de dados, produzem análises e novos benchmarks e standards, agregados mediante esquemas de financiamento de "um sistema de atração e persuasão", denominado soft governance. Muitos profissionais, voluntariamente, têm produzido novas tecnologias políticas, como novos sistemas de educação; contudo, resta saber se resolvem algo além de apenas enfrentar o ordinário. Outras questões relativas à educação na UE são discutidas por Fátima Antunes no artigo $A$ ação conjunta de organizações 
internacionais (UE e OCDE) em educação: metamorfoses? Observações em torno de políticas educativas em Portugal. Desde 2013, a OCDE vem intervindo na educação em Portugal com o objetivo de elaborar uma Estratégia Nacional de Competências, incidindo na educação de adultos; após 2017, para o ensino básico e secundário, criou o Projeto Autonomia e Flexibilidade Curricular. Ambos constituem políticas nacionais no interior do Programa Educação e Formação 2020, parte das políticas europeias para a educação. A dinâmica referida leva os técnicos da OCDE a se relacionarem diretamente com os atores escolares, bem como de outros contextos educativos. Segundo a autora, há um processo de europeização da educação e das políticas públicas para a área. De modo geral, a atuação desse tipo de organização supranacional expressa uma "nova ordem educacional associada a processos e projetos políticos de globalização e da economia do conhecimento". A trajetória da europeização da educação supõe que a mediação nacional adquire centralidade na medida em que concretiza escolhas dos governos nacionais no que se refere às orientações políticas e aos modelos educativos que tais organizações supranacionais - a exemplo da OCDE e da UE - difundem. Juntam-se, aqui, atores e contextos globais e locais, num movimento de articulações novas, "com novos papéis e protagonismos para as autoridades nacionais, bem como para as organizações internacionais e outros perfis para atores e contextos locais".

Fazendo um contraponto com os três artigos anteriores que discutiram a situação educativa na UE, o de Letícia Fiera examina uma das principais redes da América Latina e Caribe, a Rede Latinoamericana de Organizações da Sociedade Civil para a Educação (Reduca), em As teias de interesses e influências nas redes de políticas educativas na América Latina e Caribe. Para compreender as determinações mais gerais do compromisso com a privatização da educação pública na região, ela traz à luz a rede política de empresários, de grupos econômicos, de instituições financeiras e de organismos multilaterais que se articularam para intervir nas decisões relativas às políticas educativas, ressaltando-se nesse processo o Movimento Todos pela Educação, no Brasil. Para evidenciar os países, instituições e sujeitos que atuam na definição de políticas educacionais latino-americanas, a autora usou a metodologia de análise de redes sociais. Restou claro que a Reduca tem grande importância na região, congregando 14 países, com destaque para os papéis centrais do Brasil e México.

Fecha o Dossiê a entrevista realizada por Fernando Santos com Mauro lasi, Educação e organismos multilaterais: o atual estágio da luta de classes, na qual o professor analisa a conjuntura atual no país, relacionando-a, de um lado, com a política educacional e, de outro, com diretrizes emanadas de Organizações Multilaterais. Para lasi, estamos presenciando um ataque à educação pública relativo às demandas da "inflexão reacionária" no Brasil. Está em questão a substituição do "direito" à educação pela concepção de "serviço mediado pelo mercado", isto é, "um valor de uso a que só se tem acesso mediante um valor de troca". Desse modo, a educação emerge como espaço de "valorização do valor e de acumulação provada de riqueza", razão pela qual precisa ser sucateada e desqualificada, 
confirmando a ineficiência do Estado. 0 esvaziamento das práticas educativas - seja para formação profissional, pesquisa ou desenvolvimento humano - justifica sua transformação em espaço formal de certificação tendo em vista o acesso ao mercado de trabalho e a ascensão social. A eficácia projetada para a área - fazer mais com menos - é uma das teses difundidas por Organizações Multilaterais que acenam com a consecução de metas, elidindo que a formação humana está sendo destruída.

Para as organizadoras deste Dossiê, os artigos e a entrevista oferecem um rico campo de interrogação, pois mostram que ideias comuns percorrem países da UE e da América Latina e Caribe. Economia e regiões distintas - do centro e da periferia do capitalismo - comungam diretrizes assemelhadas no que toca à educação pública. No caso do Brasil, "0 crescimento exponencial das grandes escolas particulares vocacionadas ao preparo do magistério encontrou na modalidade $\mathrm{EaD}$ um campo específico de produção de lucro, suportada entretanto por um vasto programa de concessão de bolsas, públicas e privadas" (EVANGELISTA et al., 2019, p. 15). Parece ficar cristalino que interesses não totalmente explicitados na vasta documentação examinada pelos autores - mas que sabemos quais são - determinam as políticas que degradam a escola pública, degradam o trabalho docente, pois têm como alvo a formação da classe trabalhadora. Isso se verifica nos ataques que vivemos à ciência, cultura, educação, na diuturna expropriação de direitos em nome da capitalização e liquidez impetradas pelo rentismo (FONTES, 2010). A sanha do capital financeiro se espraia sobre a América Latina expondo sua face mais truculenta e sanguinária. 0 Chile, pioneiro no continente a incorporar o neoliberalismo, arde. Os levantes populares no Equador e Bolívia, além das prisões políticas no Brasil, faz subir a temperatura no continente. A luta de classes está explicitada, convocando os educadores a considerá-la em seu pensar e fazer educação.

\section{REFERÊNCIAS}

EVANGELISTA, 0. et al. Desventuras dos professores na formação para o capital. Campinas: Mercado de Letras, 2019.

FONTES, V. 0 Brasil e o capital-imperialismo: teoria e história. Rio de Janeiro: EPSJV: Ed. UFRJ, 2010.

SHIROMA, E. 0.; EVANGELISTA, 0. Estado, capital e educação: reflexões sobre hegemonia e redes de governança. Revista Educação e Fronteiras 0n-Line, v. 4, p. 21-38, 2014.

SHIROMA, E. 0;; EVANGELISTA, 0. Formação humana ou produção de resultados? Trabalho docente na encruzilhada. Revista Contemporânea de Educação, Rio de Janeiro, v. 10, p. 89-114, 2015.

Endereços para correspondência: Universidade do Oeste de Santa Catarina, Rua Getúlio Vargas, 2125, 89600-000, Bairro Flor da Serra, Joaçaba, Santa Catarina, Brasil; olindaevangelista35@hotmail.com

Roteiro, Joaçaba, u. 44, n. 3, p. 1-6, set./dez. 2019| e23373 |E-ISSN 2177-6059 
